\section{O modus operandi de Deus e a composição da comunidade cristã. Um estudo de 1 Cor 1,26-31*}

\section{José Adriano Filho}

Faculdade Unida de Vitória, Brazil

http:/ / orcid.org/0000-0002-8157-4529
Resumo: Ao analisar 1 Cor 1,26-31, este artigo procura destacar a força retórica do argumento paulino que afirma que a maior parte das pessoas a quem Deus chamou para formar a comunidade cristã em Corinto não são "sábios", "poderosos" e "de família prestigiosa", mas "as coisas loucas", "as coisas fracas", "as coisas desprezíveis" e "as coisas que nada são". Deus, ao revelar a sua sabedoria e poder na cruz de Cristo, escolhe a fraqueza e loucura do mundo, destruindo os fundamentos do orgulho humano. $\mathrm{O}$ artigo demonstra também que as declaraçóes de Paulo não podem ser desvinculadas do discurso de honra próprio da cultura grecoromana, a qual estava associada a poder, gênero e lugar social. Além da riqueza, associada às pessoas de status social elevado, havia uma hierarquia de valores que incluía linhagem familiar, conexôes com Roma e sofisticação cultural.

Palavras-chave: Cartas aos coríntios; 1 Cor 1,26-31; composição social da comunidade cristã; honra; vergonha.
God's Modus Operandi and the Composition of the Christian Community. A Study on I Cor 1:26-31

Aвstract: In analyzing 1 Cor 1:26-31, this paper seeks to highlight the rhetorical power of the Pauline argument which states that most of the people God called to create the Christian community at Corinth are not "wise," "powerful," and "from a prestigious family," but "fool things," "weak things," "despicable things," and "things that are nothing." By revealing his wisdom and power in the cross of Christ, God chooses the weakness and madness of the world, destroying the foundations of human pride. The paper also shows that Paul's statements cannot be dissociated from the Greco-Roman culture's honor discourse, associated with power, gender, and social standing. In addition to wealth, associated with people of high social status, there was a hierarchy of values that included family lineage, connections with Rome, and cultural sophistication.

Keywords: Letters to the Corinthians; 1 Cor 1:26-31; social composition of the Christian community; honor; shame.

\section{COMO CITAR:}

Filhho, José Adriano. "O modus operandi de Deus e a composição da comunidade cristâ". Theologica Xaveriana 187 (2019): 1-20. https://doi.org/10.11144/ javeriana.tx69-187.modccc

\footnotetext{
* Artigo de investigação

${ }^{a}$ Autor de correspondencia. Correio eletrônico: joseadriano@faculdadeunida.com.br
} 


\section{Introdução}

A Igreja de Corinto foi fundada pela proclamaçâo do "Cristo crucificado" (2,1-5). A "palavra da cruz", o Evangelho que Paulo proclamou aos coríntios, contradiz as expectativas humanas sobre a forma da ação de Deus, além de constituir o fundamento da verdadeira sabedoria $(1,18-25)$. A "palavra da cruz", considerada também por algumas pessoas como loucura e fraqueza, é "mais sábia e mais forte do que os homens" $(1,25)$. Este paradoxo é definido em relação à cruz de Cristo e o poder de Deus é identificado com o Messias crucificado: "a loucura de Deus" e os valores ligados a "loucura-sabedoria" e "fraqueza-força" são substituídos pelos valores centralizados na cruz ${ }^{1}$.

Paulo, então, procura demonstrar os efeitos da "palavra da cruz" na composição da comunidade cristã (1,26-31). Após declarar que a "mensagem da cruz" é poder, embora se manifeste como fraqueza, e sabedoria para "os que estáo sendo salvos", mas "loucura" e "fraqueza" para "os que "estão a caminho da destruiçáo", ele assinala as circunstâncias da formação da comunidade cristã em Corinto. Há, no seu pensamento, uma correlação entre a manifestação da "sabedoria e poder de Deus" na cruz, ou "loucura e fraqueza de Deus", e a estrutura da comunidade cristâ, pois as pessoas consideradas como "os que nada são" pela "sabedoria deste mundo" são os representantes da sabedoria que se manifesta na cruz $^{2}$.

Numa sociedade que valorizava a honra, o poder e o prestígio, a falta de status dos coríntios no momento da sua vocação é uma indicação clara da loucura de Deus. Como resultado da sua vocação por meio da loucura da proclamação da cruz, o seu status foi subvertido, isto é, eles não eram "nada", mas tornaram-se "participantes do povo de Deus". Deus salva "os que creem" pela "fraqueza" e "loucura" da cruz, e salva os que são considerados "loucos", "fracos" e "que nada são" segundo os padróes da "sabedoria deste mundo". A vocação da comunidade cristã não tem como base status sócio-econômico ou capacidade pessoal, mas o amor e a iniciativa de Deus ${ }^{3}$.

Os coríntios deveriam ver a si mesmos da perspectiva de Deus e compreender que agora, em Cristo, tornaram-se uma comunidade que dever ser caracterizada pela unidade, não pelo status social ou fidelidade a pessoas específicas, muitas das quais viam a si mesmas como superiores e causavam discórdias na comunidade (1,10-17; 3,1-4). Neste contexto, ao apresentar a composiçâo social da comunidade cristã em

${ }^{1}$ Pickett, The Cross in Corinth. The Social Significance of the Death of Jesus, 69-71.

${ }^{2}$ Strüder, Paulus um die Gesinnung Christ. Identität und Entscheidungsfindung aus der Mitte von 1 Kor 1-4, 286.

${ }^{3}$ Mihaila, The Paul-Apollos Relationship and Paul's Stance Toward Greco-Roman Rhetoric, 19-21. 
Corinto em 1 Cor 1,26-31, Paulo convida os coríntios a refletir sobre a realidade da vocação e o seu significadó.

\section{Texto e estrutura de 1 Cor 1,26-31}

1 Cor 1,26-31 inicia-se com a declaração de que os receptores da "palavra da cruz, isto é, o evangelho que Paulo anunciou em Corinto (At 18,1-11), não são os "sábios", "poderosos" e "de nobre nascimento", mas "as coisas loucas", "as coisas fracas", "as coisas desprezíveis" e "as coisas que nada são". Quem, em nome da "sabedoria deste mundo", alcançaria tal fraqueza? Quem escolheria tais pessoas para ser o novo povo de Deus? A identidade eclesial dos coríntios é uma resposta à "palavra da cruz", isto é, o evento da morte de Cristo é o fundamento da sua existência. A vocação da Igreja de Corinto é um exemplo da loucura e fraqueza de Deus que, ao revelar a sua sabedoria e poder na cruz de Cristo, escolhe a fraqueza e loucura do mundo, destruindo os fundamentos do orgulho humano'.

1 Cor 1,26-31 distingue-se do texto que o precede $(1,18-25)$ e do texto que o sucede $(2,1-5)$. O texto apresenta uma mudança de perspectiva em relação 1,18-25, pois focaliza os coríntios por meio do uso marcante do verbo na segunda pessoa do plural: "Vede", "considerem" $(1,26)$, que indica que sua vocaçáo exemplifica a loucura e fraqueza de Deus, isto é, a inversão que Deus realiza nas avaliações que envolvem a sabedoria humana no que se refere a status, realizaçóes e sucesso.

Em 1 Cor 2,1, a introdução da primeira pessoa do singular: "Eu, também, vindo a vós, irmãos", inicia o tópico que trata do modus operandi de Paulo, quando, pela primeira vez, ele proclamou a "palavra da cruz" em Corinto (2,1-5). 1 Cor 1,26-31 está também vinculado a 1,18-25 por algumas palavras-chave: as expressóes "aos que são chamados" $(1,24)$ e "as coisas loucas do mundo" (1,27a) estấo ligadas à "loucura de Deus" (1,25a) e "as coisas fracas do mundo" $(1,27 b)$ está ligado à "fraqueza de Deus" (1,25b). Paulo dá continuidade ao pensamento de 1,18-25 em 1,26-31 ao demonstrar o que havia dito antes sobre a sabedoria e loucura de Deus, reveladas na cruz de Jesus, o Messias.

1 Cor 1,26-31 contém duas partes: 1,26-29 e 1,30-31. A primeira parte demonstra que Deus chama as pessoas que estáo no lado mais baixo da sociedade, excluindo todas as instâncias que possam gerar orgulho nos que são chamados. No paralelismo

\footnotetext{
${ }^{4}$ Berger, Formas Literárias do Novo Testamento, 253-254.

${ }^{5}$ Pickett, The Cross in Corinth. The Social Significance of the Death of Jesus, 73-74.

${ }^{6}$ Strüder, Paulus um die Gesinnung Christ. Identität und Entscheidungsfindung aus der Mitte von 1 Kor $1-4,282$.
} 
antitético triplo de 1,26-28, que fala sobre os que foram "chamados", o uso da forma imperativa "vede", "considerem" $(1,26)$ assinala tanto o ato passado da vocação quanto o presente da comunidade. A presença dos “sábios segundo a carne”, "poderosos” e "de nobre nascimento" indica categorias sociológicas e, destas três categorias, "segundo a carne" é adicionado a "sábio". Paulo destaca também os objetivos da ação de Deus, a qual também determina a estrutura da Igreja: "Mas Deus escolheu as coisas loucas do mundo para envergonhar os sábios; Deus escolheu as coisas fracas do mundo para envergonhar as coisas fortes; Deus escolheu as coisas vis e as desprezíveis, aquelas que nada são, para destruir as que são" $(1,27-28)$. O uso triplo da cláusula explicativa "para" destaca a ação de Deus e constitui uma dialética entre "loucura e sabedoria", "fraqueza e poder", "os que são" e "os que nada são". A presença da cláusula explicativa "para que", na conclusão da unidade, indica que a ação de Deus é pedagógica, sendo o seu alvo "para que ninguém se vanglorie diante de Deus" $(1,29)$.

$\mathrm{Na}$ segunda parte do texto (1,30-31) Paulo explica o significado de Cristo para "aqueles que creem". A declaração: "Vós, porém, sois dele, em Cristo Jesus" (1,30a), descreve a vocação dos coríntios e corresponde a "aos que são chamados" $(1,24)^{7}$. Os quatro termos referentes à salvaçáo: "sabedoria da parte de Deus, justiça, santificação e redenção" são antitéticos em relação a "coisas loucas", "coisas fracas", "coisas vis" e "coisas que nada são". 1 Cor 1,30b oferece uma interpretação do que significa o Messias crucificado. Em 1,24, ele é apresentado como "poder e sabedoria de Deus", mas agora "tornou-se para nós, sabedoria da parte de Deus, justiça, santificação e redenção".

Paulo amplia também o seu pensamento ao citar as Escrituras Judaicas: "para que, como está escrito, 'aquele que se gloria, glorie-se no Senhor'”. Esta passagem, que corresponde a LXX Jer 9,22-23, afirma de forma positiva a ideia formulada de forma negativa em 1,29: "para que nenhuma criatura se vanglorie diante de Deus", tornando a conclusão de 1 Cor 1,26-31 uma indicação de uma atitude apropriada que se espera daqueles que foram chamados por Deus: "aquele que se gloria, glorie-se no Senhor".

$\mathrm{Na}$ declaração inicial do texto, Paulo relembra aos coríntios as suas origens humildes: "Considerai, pois, irmãos e irmãs, a vossa vocação, pois não são muitos sábios segundo a carne, nem muitos poderosos, nem muitos de família prestigiosa" $(1,26)$. O povo que Deus chamou é apresentado da perspectiva da "palavra da cruz": "Mas Deus escolheu as coisas loucas do mundo para envergonhar os sábios; e Deus

\footnotetext{
${ }^{7}$ Fee, The First Epistle to the Corinthians, 84-85.

${ }^{8}$ Strüder, Paulus um die Gesinnung Christ. Identität und Entscheidungsfindung aus der Mitte von 1 Kor 1-4, 284-285.

${ }^{9}$ Ibid., 286.
} 
escolheu as coisas fracas do mundo para envergonhar as coisas fortes; e Deus escolheu as coisas vis e as desprezíveis, aquelas que nada são, para destruir as que são" (1,27-28).

O contraste entre as perspectivas "deste mundo" e "divina" dominam o argumento apresentado: "sábios", "poderosos", "de família prestigiosa", pessoas de status elevado que o mundo valoriza, estão destinados à vergonha e destruição pela ação divina. Deus faz estas coisas ao escolher pessoas do mais baixo status social, aquelas que o mundo considera "loucas", "fracas", "desprezadas" ou "nada", sendo claro o motivo para que isso ocorra: "ninguém se glorie diante de Deus" $(1,29)$, "a salvação vem do Senhor" $(1,30)$ e "aquele que se gloria, glorie-se no Senhor" $(1,31)^{10}$.

A vocação do povo de Deus revela a intenção divina de destruir os fundamentos do orgulho que tem por base o ser humano e procura levar os coríntios a gloriaremse apenas no Deus vivo: "Vós, porém, sois dele, em Cristo Jesus, que se tornou para nós sabedoria da parte de Deus, justiça, santificação e redenção, para que, como está escrito, 'aquele que se gloria, glorie-se no Senhor'” (1,30-31).

De acordo com a sua estrutura, 1 Cor 1,26-31 pode ser apresentado da seguinte forma ${ }^{11}$ :

Parte I $\quad{ }^{26}$ Considerai, pois, irmãos e irmãs, a vossa vocação, pois não são muitos sábios segundo a carne, nem muitos poderosos, nem muitos de família prestigiosa.

${ }^{27}$ Mas Deus escolheu as coisas loucas do mundo para envergonhar os sábios;

Deus escolheu as coisas fracas do mundo para envergonhar as coisas fortes;

${ }^{28}$ Deus escolheu as coisas vis e as desprezíveis, aquelas que nada são, para destruir as que são,

Овјетіvo $\quad{ }^{29}$ para que nenhuma criatura se vanglorie diante de Deus. (NEGATivo)

PARTe II $\quad{ }^{30}$ Vós, porém, sois dele, em Cristo Jesus, que se tornou para nós sabedoria da parte de Deus justiça, santificação e redenção,

\footnotetext{
${ }^{10}$ Fee, The First Epistle to the Corinthians, 78-79; Litfin, St. Paul's Theology of Proclamation. 1 Corinthians 1-4 and Greco-Roman Rhetoric, 204.

${ }^{11}$ Kammler, Kreuz und Weisheit. Eine exegetische Untersuchung zu 1 Kor 1,10-3,4, 128-129.
} 
Овјетіvo $\quad{ }^{31}$ para que, como está escrito,

(positivo) "aquele que se gloria, glorie-se no Senhor".

\section{A ação de deus na constituição da Igreja de Corinto}

1 Cor 1,26-31 indica que Deus em Cristo realiza uma inversão das avaliaçôes humanas referentes a status, realizaçóes e sucesso ao descrever como, em sua sabedoria, Ele agiu na constituição da igreja de Corinto. A declaração inicial do texo: "Considerai, pois, irmãos e irmãs, a vossa vocação, pois náo são muitos sábios segundo a carne, nem muitos poderosos, nem muitos de família prestigiosa" $(1,26)$, destaca a ação de Deus na vocação da Igreja e convida os coríntios a discernir a sua própria realidade. A existência da comunidade cristã é uma evidência da "palavra da cruz", pois através da sua proclamação Deus rejeita aqueles que são considerados "sábios", "fortes" e "de nobre nascimento".

O texto destaca o milieu social dos coríntios ao indicar três dimensóes através das quais o status social era medido: sabedoria, poder e nobreza. A sabedoria tem precedência tanto por sua importância quanto pela intençáo do argumento paulino. "Sabedoria", "poder" e "nobreza" eram valorizados na sociedade greco-romana, mas, segundo Paulo, Deus vê as coisas de forma inversa e os termos utilizados indicam como status social elevado ou baixo era compreendido naquela época. Ele relembra aos coríntios que muitos deles não provinham dos estratos sociais elevados da sociedade, pois Deus escolheu "as coisas loucas do mundo", "as coisas fracas do mundo", "as coisas desprezíveis" e "as coisas que nada são" para compor a comunidade cristẫ ${ }^{12}$.

A composição social da comunidade cristã em Corinto ilustra o princípio que indica que Deus utiliza o que o mundo considera de menor valor. Paulo utiliza também este princípio para justificar o seu modus operandi como pregador $(2,1-5)$, e é crucial que os coríntios o apreendam, pois, em geral, eles não pertenciam aos grupos sociais elevados da cidade. Alguns deles, não muitos, eram "sábios", "poderosos" e de "nobre nascimento" $(1,26)$, mas a maior parte dos membros da comunidade cristã não tinha uma posição social de destaque na cidade ${ }^{13}$. De acordo com esse princípio,

${ }^{12}$ Voss, Das Wort vom Kreuz und die menschliche Vernunft, 110-111; Horrell, The Social Ethos of the Corinthians Correspondence. Interests and Ideology from 1 Corinthians to 1 Clement, 132; Litfin, Paul's Theology of Proclamation, 203-204; Finney, Honour and Conflict in the Ancient World. 1 Corinthians in its Greco-Roman Social Setting, 95-98.

${ }^{13}$ Hays, First Corinthians, 32-33, declara: "Even though a few members of the community may have enjoyed relative affluence, this Church is on the whole not a gathering of the elite. "Not many" of them were highly educated or wealthy or powerful. Nonetheless, as Paul has insisted, they have been called by God as God's own covenant people (1:2). [...]. God has not called Caesar or persons of senatorial rank to 
Deus escolheu as pessoas que não são valorizadas pela sabedoria deste mundo para subverter aquilo que Ele atribui valor e considera elevado. A mençáo destes grupos indica também que "mensagem da cruz" tem um amplo horizonte, pois ela provoca uma crise na "sabedoria deste mundo" e em tudo aquilo que serve de base para o orgulho humano $(1,29)^{14}$.

Os grupos sociais que compóem a comunidade cristá são apresentados a partir de um paralelismo antitético triplo, o qual destaca a ação de Deus e sujeita a estrutura social da igreja a uma interpretação da perspectiva da cruz: Deus escolheu "não muitos sábios", "poderosos" e "de nobre nascimento", mas "as coisas loucas", "as coisas fracas", "as coisas desprezadas" e "as coisas que nada são" para "reduzir a nada as que são" 15

\begin{tabular}{|l|l|l|l|}
\hline $\begin{array}{c}\text { GRUPO DE PESSOAS } \\
\text { NÁO ESCOLHIDAS }\end{array}$ & $\begin{array}{l}\text { GRUPO DE PESSOAS } \\
\text { ESCOLHIDAS }\end{array}$ & AÇÃo DE DEUS & \multicolumn{1}{|c|}{$\begin{array}{c}\text { OBJETIVO DA } \\
\text { ESCOLHA DIVINA }\end{array}$} \\
\hline não muitos sábios & $\begin{array}{l}\text { mas as coisas loucas } \\
\text { do mundo }\end{array}$ & Deus escolheu & $\begin{array}{l}\text { para envergonhar } \\
\text { os sábios }\end{array}$ \\
\hline $\begin{array}{l}\text { não muitos pode- } \\
\text { rosos }\end{array}$ & $\begin{array}{l}\text { as coisas fracas do } \\
\text { mundo }\end{array}$ & Deus escolheu & $\begin{array}{l}\text { para envergonhar } \\
\text { as coisas fortes }\end{array}$ \\
\hline $\begin{array}{l}\text { não muitos de } \\
\text { família prestigiosa }\end{array}$ & $\begin{array}{l}\text { as coisas vis do } \\
\text { mundo, e as coisas } \\
\text { desprezíveis (...) as } \\
\text { que nada são }\end{array}$ & Deus escolheu & $\begin{array}{l}\text { para destruir as que } \\
\text { são }\end{array}$ \\
\hline
\end{tabular}

Nestes versos, o uso das desconcertantes formas neutras "as coisas loucas", "as coisas fracas", "as "coisas desprezadas" e "as coisas que nada são" indica que a escolha das pessoas que compóem a comunidade está relacionada com a sabedoria e poder de

represent the Gospel in the world; instead, he has called this motley assembly which embraces freedmen, trades people, and slaves — along with a few people of higher standing (hence "not many", rather than "none"). This mixed socioeconomic status of the Church was one of the most striking features of the early Christian movement. [...]. The fact that early Christian assembly brought together people of diverse rank and background who aknowledge one another as "brothers and sisters" (v. 26) was one of its distinctive characteristics". Cf. também Theissen, The Social Setting of Pauline Christianity. Essays on Corinth, 70-71; Clarke, Secular and Christian Leadership in Corinth: A Socio-Historical and Exegetical Study of 1 Corinthians 1-6; Barclay, "Thessalonica and Corinth: Social Contrasts in Pauline Christianity", 49-74.

${ }^{14}$ Litfin, St. Paul's Theology of Proclamation, 203; Voss, Das Wort vom Kreuz und die menschliche Vernunft, 112.

15 Ibid., 113; Horrell, The Social Ethos of the Corinthians Correspondence. Interests and Ideology from 1 Corinthians to 1 Clement, 132-133. 
Deus que se manifestam no Messias crucificado (1,18-25). A antítese "as coisas que nada são", "as coisas que são", o terceiro membro da antítese, é o clímax da apresentaçâo paulina, que destaca "as coisas desprezadas" e "as coisas que nada são" como objeto da eleiçẫo divina ${ }^{16}$.

Os "sábios" e "poderosos" são apresentados como objeto do verbo "envergonhar" $(1,27)$ e "as coisas que são" como objeto do verbo "destruir" $(1,28)$. A palavra da cruz está relacionada com a vocação e o juízo e recriação escatológicos. A comunidade cristã assemelha-se à criação ex nihilo e, em conexão com "os que nada são", a ação de Deus difere do pensamento das pessoas cuja atenção concentra-se apenas em "sinais" e "sabedoria" $(1,22)^{17}$. Os termos relacionados com "inteligência" ("sábios"), "influência” ("poderosos") e "status elevado" ("de família prestigiosa”) que estes versos apresentam estão também invertidos e redefinidos na referência a justiça, santidade e redenção: "Vós, porém, sois dele, em Cristo Jesus, que se tornou para nós sabedoria da parte de Deus, justiça, santificação e redenção" $(1,30)^{18}$.

\section{Inversão do ethos cultural greco-romano referente a status social}

As declaraçóes de Paulo não podem ser desvinculadas do discurso de honra próprio da cultura greco-romana, que em geral classificava as pessoas em pessoas em honestiores (pessoas de status social elevado) e humiliores (pessoas de status social inferior). A riqueza estava associada a pessoas de status social elevado, além da linhagem familiar, conexôes com Roma e sofisticação cultural. A honra tinha grande valor simbólico e

\footnotetext{
${ }^{16}$ Theissen, The Social Setting of Pauline Christianity. Essays on Corinth, 71-72: "When repeating the idea

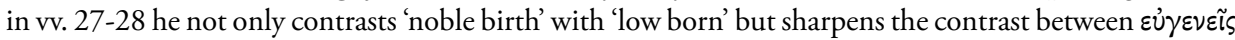

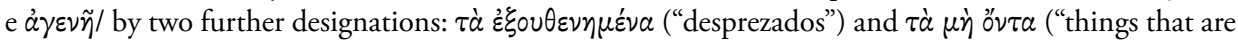
not"). Altough it is true that by means of these designations social relationships are seen in a theological light, the sociological implications of the concepts cannot be denied. [...]. This when Paul writes that those whom society and the world (xó $\sigma \mu \circ, 1$ Cor. 1:28) regard as nothing are in reality representatives of that true wisdom which is contained in Christ, his Greek diction reveals how others perceive the social status of those whom he is addressing. This becomes clearer with the supplementary, appositive phrase $\tau \dot{\alpha} \mu \dot{\eta}{ }^{\prime} v \tau \alpha[. .$.$] . Because this particular term in the series goes beyond the catchword of the preceding$ context, it can be assumed that in the new paragraph (1Cor. 1:26ff.) Paul has a social fact in mind and probably intends the first two categories to be understand sociologically as well. The 'powerful' would be influential people; the 'wise', those who belonged to the educated classes (that is, 'wise according to the worldly standards') for whom wisdom is also a sign of a social status. Unless Paul had also been thinking in these instances of sociological criteria he could scarcely have combined the three terms and, taking them collectively, contrasted to them the election of those who are not, $\tau \dot{o} \mu \dot{\eta} \tilde{\omega} \nu "$ (ibid.).

${ }^{17}$ Voss, Das Wort vom Kreuz und die menschliche Vernunft, 113-115; Conzelmann, 1 Corinthians, 41-42.

${ }^{18}$ Thiselton, The First Epistle to the Corinthians, 178.
} 
estava associada a poder, gênero e lugar social, sendo insuportável para uma pessoa perder a sua honra; as pessoas do mundo mediterrâneo daquela época eram educadas a buscar a honra e evitar a vergonha.

"Honra" e "vergonha" eram valores sociais centrais para elas. Como honra envolve comportamentos, compromissos e atitudes que visavam preservar a cultura e a sociedade, a tendência das pessoas criadas naquele contexto era buscar o bem do grupo maior, incorporando voluntariamente os seus valores como caminho para a realização pessoal ${ }^{19}$.

Algumas pessoas da igreja de Corinto pertenciam aos estratos superiores da sociedade ${ }^{20}$. A elite social da cidade incluía escravos libertos e veteranos. Alguns comerciantes e artesãos eram destacados e tinham aspiraçôes sociais, mas precisavam participar de clubes próprios para criar um vínculo social e identidade. "Ser honrado" significava "ser", então o questionamento que Paulo faz aos coríntios, que pressupóe que honra significa ser "sábio", "poderoso" e "nobre", desafiava o próprio "ser" dos coríntios.

As pessoas cujo status dependia da riqueza recém-adquirida tinham papéis proeminentes não só na sociedade em geral, mas também na Igreja. Desta forma, as palavras de Paulo são dirigidas a pessoas sedentas por status $(1,26)$; de fato, a inconsistência de status estava na raiz da atração que o cristianismo exercia sobre algumas pessoas da Igreja de Corinto: a nova religião deu-lhes um status que eles não haviam alcançado naquela sociedade.

Paulo estava lidando com o "ser" dos coríntios ao lembrá-los quem eram quando foram chamados. A vocação divina deu-lhes um "novo ser", embora pareça que eles haviam esquecido esta realidade devido a sua ligação com o ethos social vigente. O novo ser "em Cristo" deu aos coríntios uma identidade, razão porque o questionamento do seu status por Paulo visava, paradoxalmente, reafirmar o seu "ser" e identidade ${ }^{21}$.

Os termos usados por Paulo, "sábios", "poderosos" e "de família prestigiosa", representam tudo aquilo que as pessoas desejavam alcançar, de acordo com o ethos social e cultural greco-romano ${ }^{22}$. Neste sentido, é natural que Paulo procure lidar com os coríntios de forma a indicar uma drástica inversão deste ethos social e cultural. Esta linguagem indica também a força da retórica do argumento paulino. Os coríntios

\footnotetext{
${ }^{19}$ De Silva, The Hope of Glory: Honor Discourse and the New Testament Interpretation, 2-3.

${ }^{20}$ Meeks, Os primeiros cristãos urbanos. O mundo social do apóstolo Paulo, 121-167.

${ }^{21}$ Witherington, Conflict and Community: A Socio-Rhetorical Commentary on 1 and 2 Corinthians, 23-24; Friesen, "Prospects for a Demography of the Pauline Mission: Corinth among the Churches", 351-370.

22 Thiselton, The First Epistle to the Corinthians, 182-183.
} 
estavam competindo por status, mas Paulo ressalta o absurdo de tais lutas à luz da sua própria realidade quando Deus os chamou.

Eles foram chamados não porque tinham status, pelo contrário, Deus escolheu usar coisas e pessoas que não tinham status. Deus inverte os valores vigentes ao valorizar "os que nada são", razão porque o comportamento jactancioso e divisivo dos coríntios é absurdo no contexto da narrativa das origens da comunidade apresentado ${ }^{23}$. É como se Paulo dissesse: "Vocês estâo preocupados com poder e status social, então examinem a questão a partir do vosso próprio padrão de pensamento. No final deste processo, vocês mesmos reconhecerão que, na realidade, náo muitos de vocês pertencem aos grupos sociais elevados da cidade"; embora houvesse algumas destas pessoas pertencessem a estes estratos, a maioria delas pertencia aos grupos do mais baixo status social. Mas, ironicamente, porque "poucas pessoas" pertenciam aos estratos sociais elevados, elas tornaram-se importantes e influentes, fazendo valer cada vez mais a sua posição social.

Por essa razão, na declaração de 1,29, introduzida pela partícula "para que", Paulo expressa o propósito último da loucura de Deus: "para que nenhuma criatura se vanglorie diante de Deus" ${ }^{24}$. Deus realiza uma inversão nos valores da "sabedoria deste mundo". De alguma forma, o uso da partícula adversativa "mas" antecipa esta inversão: "Mas Deus escolheu as coisas loucas do mundo para envergonhar os sábios; e Deus escolheu as coisas fracas do mundo para envergonhar as coisas fortes; e Deus escolheu as coisas vis e as desprezíveis, aquelas que nada são, para destruir as que são" $(1,27-28)$.

Deus escolhe as coisas loucas do mundo, a cruz e "os que creem". O princípio que subjaz à sua ação ao chamar os coríntios para participar da comunidade combina com a fraqueza e loucura da cruz. Deus, ao chamá-los, mostra ao mundo como Ele é, sua ação, mas o objetivo de Paulo é remover dos coríntios qualquer motivo para eles se orgulharem ${ }^{25}$. A base do gloriar-se dever ser a cruz de Cristo, não as realizações ou o prestígio atribuído às pessoas.

$\mathrm{Na}$ estrutura escatológica do pensamento paulino, o "sábio", o "escriba" e o "inquiridor deste século" $(1,20)$ não têm mais lugar na nova era inaugurada pela cruz de Cristo. Os "sábios" e "poderosos" são apresentados como objeto do verbo "envergonhar" $(1,27)$ e "as coisas que são" como objeto do verbo destruir $(1,28)$. O texto paulino inicia-se com a apresentaçấo das pessoas "insignificantes", acrescenta

\footnotetext{
${ }^{23}$ Pogoloff, Logos and Sophia. The Rhetorical Situation of 1 Corinthians, 203.

${ }^{24}$ Thiselton, The First Epistle to the Corinthians, 187.

${ }^{25}$ Voss, Das Wort vom Kreuz und die menschliche Vernunft, 109-110; Best, "The Power and Wisdom of God", 38.
} 
“desprezíveis" e, numa forma retórica típica que inclui os coríntios, classifica-os como "coisas que nada são" e escolhidos por Deus "para destruir as coisas que são"26.

O verbo "destruir" expressa a convicção de que, em Cristo, Deus já colocou o futuro em movimento, razão porque a "era presente" está sendo deixada de lado pela ação divina. Deus chamou os coríntios para participar da sua glória $(2,7)$ e escolhe "as coisas que nada são" para destruir as coisas que são", isto é, os "sábios", "poderosos" e "de família prestigiosa" desta era. Paulo rompe com as expectativas associadas a status do seu público. Para ele, no Cristo crucificado os coríntios têm uma fonte comum de salvação e um paradigma de liderança.

Ele não dispensa os termos referentes a status elevado e, tampouco, ataca a hierarquia e prega a igualdade, mas apropria-se de termos como "sabedoria" e "poder" e os apresenta em linguagem apocalíptica: Deus escolhe a loucura e derruba o que é considerado elevado por meio de algo considerado desprezível. Na sua sabedoria e poder todas as qualidades humanas tornam-se tolas e fracas $(1,25)$. O mundo apocalíptico não dissolve as hierarquias existentes numa igualdade. Nele, os valores do mundo greco-romano são reconhecidos, mas invertidos. $\mathrm{O}$ evangelho apocalíptico revela a instabilidade dos valores da cultura greco-romana e os substitui por um mundo no qual o que é elevado torna-se baixo, é o que é baixo torna-se elevado ${ }^{27}$.

A "palavra da cruz" está, portanto, relacionada tanto com a vocação quanto o juízo e recriação escatológicos. A cruz de Jesus e sua proclamação realiza o que na tradição apocalíptica era esperado para o fim dos tempos, ou seja, o fim dos governantes e poderosos deste mundo. A destruição "das coisas que são" e a escolha "das coisas que não são" significa não somente a transformação de categorias humanas de julgamento, mas também a relativização completa de todos esses valores na cruz de Jesus, o Messias.

As categorias sociológicas que Paulo apresenta são importantes em relação à vocação, não porque os "sábios", "poderosos" e "de família prestigiosa” estão excluídos da salvação, pois pela palavra da cruz eles são libertados da posse da sua sabedoria, poder e nobreza. Paulo também não desconsidera a situação do ser humano, pois uma pessoa pode considerar sua humildade como privilégio e, assim, vangloriar-se.

A exclusão de todos os privilégios e a possibilidade de "gloriar-se apenas no Senhor" $(1,31)$ é, no entanto, o cerne do texto. A declaração de 1,29: "para que nenhuma criatura se vanglorie diante de Deus", na qual "para que" opóe-se formalmente às proposiçôes formuladas com o uso de "para" anteriores: "para envergonhar os sábios", "para envergonhar as coisas fortes", "para destruir as coisas que são" (1,27-28),

\footnotetext{
${ }^{26}$ Martin, The Corinthian Body, 59-60.

${ }^{27}$ Fee, The First Epistle to the Corinthians, 83.
} 
demonstra o objetivo final assinalado pelos verbos "envergonhar" $(1,27)$ e "destruir" $(1,28)$, pois quando Deus se volta para "aqueles que nada são" qualquer tipo de vanglória torna-se um absurdo ${ }^{28}$.

\section{Os coríntios devem agir de acordo com os padrões que a cruz apresenta}

$\mathrm{Na}$ Igreja de Corinto algumas pessoas viam a si mesmas, a Paulo e aos demais líderes de uma forma equivocada, pois o faziam segundo os padróes da "sabedoria deste mundo", isto é, utilizavam os critérios de prestígio e honra vigentes no mundo greco-romano para avaliar a si mesmos. Paulo, contudo, emprega as expressóes: "louco"/"sábio", "fraco"/“forte”, "desprezados"/“de família prestigiosa”, "coisas que nada são"/“coisas que são" (1,26-28) ao criticar os padrōes de julgamento baseados em status cultural, social e de nascimento, reorientando os coríntios a agir de acordo com os padróes que a cruz apresenta. O "gloriar-se" em pessoas caracterizava a conduta dos coríntios e a estima que eles tinham por algumas pessoas, embora a maior parte deles nem sequer pertencesse aos círculos mais ricos e influentes da cidade ${ }^{29}$.

Paulo, então, redefine os padróes pelos quais os coríntios deveriam avaliar a si mesmos, estabelece os fundamentos apropriados para o "gloriar-se" e apresenta uma distinção entre um "gloriar-se" que é aceitável e um "gloriar-se" não aceitável $(1,29)^{30}$. Os coríntios deveriam "gloriar-se" somente no Senhor $(1,31)$. Este aspecto positivo é fundamentado com citação de LXX Jer 9,22-23 (1,31), que afirma que o "gloriar-se" justifica-se apenas diante da ação divina.

De acordo com Paulo, os valores sabedoria, riqueza, poder e alto status social, nos quais algumas pessoas confiavam, são frágeis como base para o seu orgulho e elas não encontrariam favor algum diante de Deus ao buscar expressar os seus privilégios desta maneira. Ele relembra escolha paradoxal de Deus das pessoas que compunham a comunidade $(1,27-28)$, algo evidente no fato de que sua maior parte foi escolhida dentre as "coisas que nada são".

Com esta declaração, Paulo expressa o propósito último da loucura divina: "para que nenhuma criatura se vanglorie diante de Deus" $(1,29)$, e apela aos coríntios para eles não se orgulharem em seus privilégios sociais diante de Deus e da comunidade, mas apenas em Cristo: "Vós, porém, sois dele, em Cristo Jesus, que se tornou para

\footnotetext{
${ }^{28}$ Voss, Das Wort vom Kreuz und die menschliche Vernunft, 115-117.

${ }^{29}$ Kwon, 1 Corinthians. Reconstructing its Social and Rhetorical Situation, 145-146.

${ }^{30}$ Donahoe, "From Self-praise to Self-boasting: Paul's Unmasking of the Conflicting Rhetoric-Linguistc Phenomena in 1 Corinthians", 78.
} 
nós sabedoria da parte de Deus, justiça, santificação e redenção, para que, como está escrito, 'aquele que se gloria, glorie-se no Senhor'” $(1,30-31)^{31}$.

O fundamento para gloriar-se rem como referência a cruz; ninguém tem privilégios diante de Deus, seja influência, bens ou prestígio. Ao escolher "os que nada são" para formar a comunidade cristã, Deus remove qualquer sistema humano imaginável que procure obter o seu favor. Neste sentido, a primeira sentença de 1,30-31 relembra aos coríntios que sua própria vocação, como a cruz, expressa "a loucura de Deus, que é mais sábia do que a sabedoria humana" $(1,25)$. Mas o que foi dito antes de forma negativa, isto é, Deus anula a sabedoria humana (1,20-21), "de modo que nenhuma criatura possa gloriar-se na presença de Deus” (1,29), agora, na forma de contraste, Paulo expressa o que Deus fez aos coríntios ao chamá-los para participar da comunidade cristã $(1,30-31)$.

Paulo utiliza o verbo "gloriar-se" $(1,29)$ devido ao seu uso em LXX Jer 9,23b, o texto que ele cita em 1,31: "a fim de que, como está escrito, 'aquele que se gloria, glorie-se no Senhor". Sua declaração: "Vós, porém, sois dele, em Cristo Jesus" (1,30a), isto é, em contraste com "este mundo" vocês devem sua existência como comunidade à ação de Deus, efetivada na história através de Jesus Cristo, "poder e sabedoria de Deus". Cristo tornou-se para nós a verdadeira sabedoria, a qual é, entâo, interpretada em termos soteriológicos, "isto é, nossa "justiça, santificação e redenção". Em 1,30, o uso de "dele" representa a vocação e corresponde a "aos que são chamados" $(1,24)$. Cristo tornou-se para nós "sabedoria", não a sabedoria "deste mundo", tão apreciada pelos coríntios, mas a verdadeira sabedoria que deve ser entendida a partir das metáforas que se referem ao ato salvador de Jesus Cristo: "justiça, santificação e redenção"32.

${ }^{31}$ Kammler, Kreuz und Weisheit. Eine exegetische Untersuchung zu 1 Kor 1,10-3,4, 136. Kammler declara:

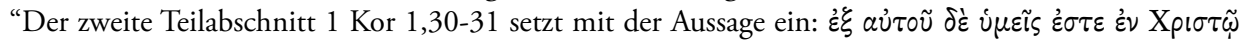

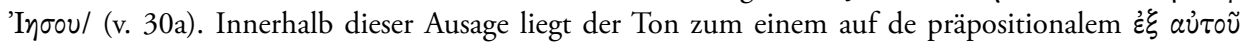

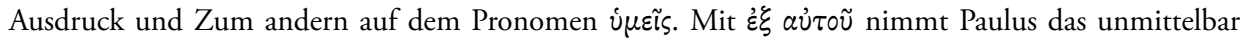

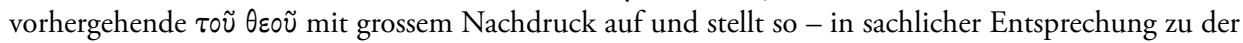

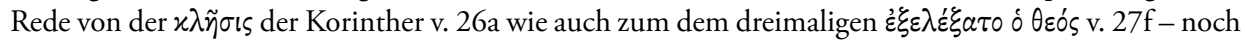
einmal emphatischer heraus, dass die Korinther ihr Sein 'in Christus Jesus' und also ihre eschatologische Neuexistenz einzig und allein Gott zu verdanken haben. Die engste Sachparallele zum dem von 1 Kor 1,30a findet sich in 2 Kor 5,18, wo Paulus die mit dem Sein év Xpı $\sigma \tau \tilde{\omega} \mid$ gegebene 'neu Existenz' $(5,17)$

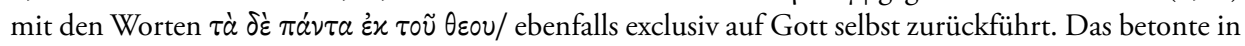
ن́ $\mu \varepsilon$ ऽ 1 Kor 1,30a verweist die Korinther auf den Gegensatz, der zwischen dem, was sie der Welt galten und noch gelten, um dem, was sie durch Gottes Heilshandeln na ihnen sind, besteht. Sucht man die Worte, die in v. 30a den Aksent tragen, in einer Paraphrase entsprechend hervorzuheben, so kann der Satz wie folgt umschrieben werde: 'Gottes Werk ist es, dass iher nach weltlichen Masstäben nichts geltet, in Christus Jesus und damit im Heil seid'” (ibid.).

${ }^{32}$ Fee, The First Epistle to the Corinthians, 85-86; Kammler, Kreuz und Weisheit. Eine exegetische Untersuchung zu 1 Kor 1,10-3,4, 138-139. Kammler afirma: "Was die synktaktische Struktur des 
Destas três palavras, a primeira delas, "justiça”, ocorre somente em 1,30 em 1 Coríntios, mas o verbo cognato "justificar" ocorre em 4,4 e 6,11. O verso está também associado a 2 Cor 5,21: “para que nele nos tornássemos justiça de Deus”. Em 1,30 há uma identificação correspondente: tudo tem origem em Deus: Deus é quem origina a nossa justiça, santificação e redenção. Esta justiça, da qual Deus é tanto a origem quanto o sujeito ativo, não é a nossa justiça, mas a justiça de Deus por nós que se tornou uma realidade efetiva ${ }^{33}$.

A segunda palavra, "santificação", deriva do âmbito do culto e significa estar próximo de Deus por meio do que Ele realizou. Neste sentido, a inversão do que significa a ausência de status e autoestima provocada pela cruz, numa cultura honra, vergonha ou culpa, significa ser revestido da justiça de Cristo como alguém amado, aceito, purificado, separado como convidado privilegiado junto a Deus e identificado com o seu nome em Cristo $^{34}$.

O terceiro termo, "redenção", deriva da linguagem do mercado de escravos do mundo greco-romano e assinala a mudança de situaçáo de uma pessoa, por meio da qual ela conseguia sua liberdade. Havia uma mudança de senhorio e o preço da liberdade era, de alguma forma, pago por alguém. Redenção significa a libertação de um estado de escravidão, dificuldade, sofrimento ou humilhação; a palavra, de alguma forma, envolvia um preço, independentemente da identidade de quem o pagava, mas a libertação conduzia a uma nova forma de serviço ${ }^{35}$.

\section{O equívoco do "orgulhar-se" na sabedoria humana}

Jesus Cristo, o crucificado, não é simplesmente fonte ou mediador da sabedoria, mas a sabedoria de Deus, isto é, "justiça", "santificaçáo" e "redençáa" ${ }^{36}$. Como algumas

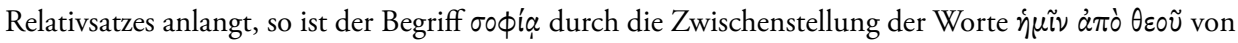

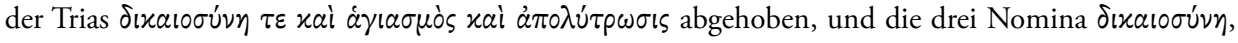

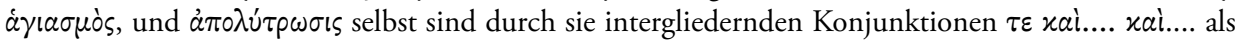
eine zusammengehörige Einheit gekennzeichnet. Darüber hinaus will beachtes sein, dass zwischen o̊

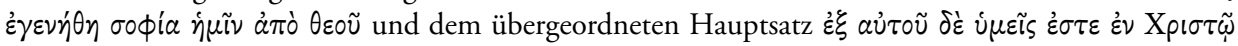

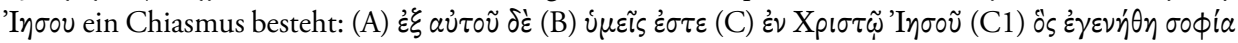

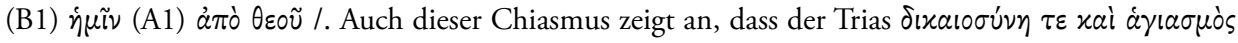
xai ả $\pi 0 \lambda u ́ \tau \rho \omega \sigma \iota \varsigma$ gegenüber den voraufgehenden Worten des Relativsatzes eine gewisse Selblständigkeit zukommt" (ibid).

33 Thiselton, The First Epistle to the Corinthians, 193.

${ }^{34}$ Ibid., 193-194.

${ }^{35}$ Ibid., 194.

${ }^{36}$ Okambawa, Paulus und Sophia. Eine exegestisch-rhetorische Untersuchung zu 1Kor 1,10-31, 251-252. 
pessoas de Corinto valorizavam a sabedoria "deste mundo" e seus privilégios sociais na comunidade cristẩ ${ }^{37}$, Paulo utiliza a estrutura hermenêutica de LXX Jer 9,22-23, ressignifica a exortação que o profeta dirigiu aos israelitas e procura redefinir os seus padróes de pensamento e ação de acordo com a sabedoria de Deus. A alusão ao texto de Jeremias: "Assim diz o Senhor: Não se glorie o sábio na sua sabedoria, nem se glorie o forte na sua força, nem o rico na sua riqueza. Mas o que gloriar-se, glorie-se nisto: em me conhecer e saber que eu sou o Senhor, que faço misericórdia, juízo e justiça na terra; nestas coisas eu me alegro, diz o Senhor", introduz o tema "orgulharse" em símbolos de status (sabedoria, influência política e nobreza) e define o que é a verdadeira sabedoria ${ }^{38}$.

A "sabedoria deste mundo" honra os "sábios, poderosos e de família prestigiosa", mas Deus exalta "as coisas desprezíveis" e "que nada são". Ele escolhe as "coisas loucas deste mundo" para envergonhar os "sábios" e as "coisas fracas deste mundo" para envergonhar os "fortes" (1,27-28; 3,18-19). O paradoxo da ação de Deus manifesta-se no amor que Ele demonstra às próprias pessoas que são consideradas pela sabedoria "deste mundo" como loucura, fraqueza e insignificância.

A alusão a Jer 9,22-23 assinala também o equívoco do que significa "orgulharse" na "sabedoria humana", na "força" e na "riqueza". Da mesma forma que o profeta Jeremias, Paulo condena o "orgulhar-se" em sabedoria, poder e nobreza ${ }^{39}$. Ao confiar na sabedoria, poder e riqueza os israelitas tinham rompido a aliança. Considerando a obsessão de Israel com a sabedoria, poder e riqueza como idolatria e loucura, Jeremias compreende que este "orgulhar-se" é fundamento para o julgamento divino, pois além de não ser um gloriar-se no Senhor e nos seus atos salvadores, torna-se um meio de autoglorificação. Jeremias contrasta duas perspectivas alternativas através de duas tríades: "sabedoria", "força" e "riqueza" e "amor", "justiça" e "equidade".

Em vez de "orgulhar-se" em coisas que podem gerar sentimentos de autossuficiência, o único fundamento para "gloriar-se" é a compreensão e conhecimento do Senhor, que faz misericórdia, justiça e equidade $(9,23)$. "Sabedoria", "poder" e "riqueza” estão, desta forma, subordinados à compreensão e conhecimento do Senhor. Não há fundamento algum para "orgulhar-se" em nada, a não ser no Senhor. Jeremias, portanto, faz uma distinção entre o "orgulhar-se" legítimo, limitado a "orgulhar-se" no nome do Senhor, e o "orgulhar-se" ilegítimo, isto é, "orgulhar-se" na arrogância de uma pessoa. No "orgulhar-se" legítimo a confiança da pessoa está no Senhor; no

\footnotetext{
${ }^{37}$ Kwon, 1 Corinthians. Reconstructing its Social and Rhetorical Situation, 150.

${ }^{38}$ Heil, The Rhetorical Role of Scripture in 1 Corinthians, 37-38.

${ }^{39}$ O'Day, “Jeremiah 9:22-23 and 1 Corinthians 1:26-31: A Study in Intertextuality", 103-132.
} 
"orgulhar-se" ilegítimo está nas "coisas deste mundo". "Sabedoria”, "poder" e "riqueza" não são coisas em si mesmas proibidas, mas quando se tornam objeto de orgulho transformam-se em ídolo, autoglorificação e autossuficiência. A posse da "sabedoria", "poder" e "riqueza" não é uma base adequada para o "orgulhar-se", pois "aquele que se orgulha deve fazê-lo porque compreende e conhece o Senhor" (Jr 9,23) ${ }^{40}$.

$\mathrm{Na}$ Igreja de Corinto, algumas pessoas colocavam a sua confiança na sabedoria, poder e nobreza de nascimento. Paulo, então, utiliza o texto de LXX Jr 9,22-23 para desenvolver a ideia de "orgulhar-se" e redefini-la em termos do conhecimento de Deus e condenar o orgulho na sabedoria "deste mundo", "poder" e "riqueza"41. Ele referese exlicitamente a esta passagem duas vezes (1 Cor 1,31; 2 Cor 10,17) e alude a ela duas vezes (1 Cor 3,21; 4,6) com o objetivo de exortar os coríntios a "orgulhar-se" no Senhor e não no ser humano.

"Sabedoria", "poder" e "riqueza" não constituem uma base adequada para o "gloriar-se". Em vez disso, aquele que se "gloria" deve "gloriar-se" em sua compreensão e conhecimento de Deus. Desta forma, Paulo introduz a verdadeira forma pela qual os coríntios devem consideram sua vocação e, embora o movimento do seu pensamento entre uma forma negativa de "orgulhar-se" a uma positiva siga o modelo de Jeremias, a inserção de Cristo estabelece uma distinção entre o seu texto e o texto de Jeremias.

Ao acrescentar a categoria cristocêntrica, o seu texto destaca o "orgulhar-se" nos atos salvadores de Deus em Cristo, o único fundamento para o "gloriar-se". Jeremias afirma que a verdadeira fonte da identidade da comunidade é a compreensão e conhecimento do Senhor, mas Paulo afirma que a fonte da identidade é Cristo, "poder e sabedoria de Deus" $(1,24)$. "Vós, porém, sois dele, em Cristo Jesus" $(1,30)$ indica que os coríntios se encontram "entre os que creem" e demonstra quão diferente significa ser "os que estão sendo salvos" (1,18-25). Os coríntios foram chamados e têm o status de nova criação $(2$ Cor 5,17$)$. Eles pertencem a Cristo como pessoas e como corpo, isto é, como a comunidade dos que creem $^{42}$.

$\mathrm{Na}$ estrutura escatológica do pensamento de Paulo, Deus elimina o que a "sabedoria deste mundo" coloca em primeiro lugar. O processo escatológico que teve início com a morte e ressurreição de Cristo ocorrerá totalmente na parousia, quando Deus exaltará não apenas os que creem e pertencem à elite social de Corinto, mas também os que creem e são considerados "loucos", "fracos" e "desprezados". Deus reduzirá a

${ }^{40}$ Donahoe, "From Self-praise to Self-boasting: Paul's Unmasking of the Conflicting Rhetoric-Linguistc Phenomena in 1 Corinthians", 83-84.

${ }^{41}$ Ibid., 84.

${ }^{42}$ Donahoe, "From Self-praise to Self-boasting: Paul's Unmasking of the Conflicting Rhetoric-Linguistc Phenomena in 1 Corinthians", 85-86. 
nada "as coisas que são", isto é, as coisas que resultam em status social - sabedoria, poder e riqueza.

Ao destruir as noções de status social e autoestima, o Senhor escolhe redimir aqueles "que nada são", "de modo que ninguém possa gloriar-se diante dele" $(1,29)$. A vocação não muda necessariamente o status social daqueles que creem (cf. 1 Cor 7,17-24), mas os que creem e são desprezados de acordo com os padróes de pensamento "deste mundo" ganham um novo status diante de Deus. Os coríntios não fizeram nada para alcançar este status redentivo, então não há motivo algum para o seu orgulho. Nenhum ser humano, quando se considera o seu lugar social - educação, influência política ou afluência social -, pode gloriar-se diante de Deus ${ }^{43}$.

\section{Conclusão}

Neste artigo ficou demonstrado como Paulo procura levar os coríntios a tomarem consciência de quem eram no tempo da sua vocação e refletir sobre o seu significado. A vocação não se baseia em status social ou na capacidade das pessoas, mas no amor e iniciativa divinos. Os coríntios deveriam ver a si mesmos da perspectiva de Deus para compreender que agora em Cristo são uma comunidade que deve ser caracterizada pela unidade, não preocupada com status social e pela fidelidade a esta ou aquela pessoa.

A tríade "sábios", "poderosos" e "de família prestigiosa", além de ser um comentário sobre a composição social da comunidade, contém também os termos de uma crítica teológica que procura refletir sobre a arrogância que ameaçava dividi-la ${ }^{44}$. Através da apresentação do status social dos crentes de Corinto Paulo destaca não o seu status social, mas a sua relaçáo com Cristo, além de desafiar a ascensão social e a estima dos coríntios pelo seu próprio status ${ }^{45}$. Ele vê o seu lugar social como um testemunho do poder e sabedoria de Deus.

As três cláusulas paralelas de 1,27-28 indicam "quem" Deus escolheu e "porque" os escolheu. Os termos "loucos", fracos", "insignificantes" e "os que nada são" referemse às pessoas que Deus escolheu, ao contrário da tríade "sábios", "poderosos" e "de nobre nascimento" $(1,26)$. O paradoxo do plano de Deus é ilustrado em seu amor e graça que se estende às pessoas que, segundo os padróes da sabedoria "deste mundo", são consideradas "loucas", "fracas", "insignificantes" e "que nada são".

Os efeitos da derrubada dos valores da sabedoria "deste mundo" são evidentes na composição da comunidade cristã. Como a estratificação social da comunidade

${ }^{43}$ Ibid., 82-83.

${ }^{44}$ O’Day, “Jeremiah 9:22-23 and 1 Corinthians 1:26-31: A Study in Intertextuality”, 264.

${ }^{45}$ Thiselton, The First Epistle to the Corinthians, 178. 
agravava as dissensões na comunidade cristã, o texto procura legitimar teologicamente uma comunidade composta na sua maior parte por pessoas de nível social mais baixo em comparação com poucas pessoas de status social elevado que pertenciam à comunidade cristá. De fato, as pessoas que a sociedade e o mundo consideram como "nada" são os representantes da sabedoria que se manifesta no Cristo crucificado.

Nesse sentido, a função crítica da teologia da cruz é relevante e a especificidade da descrição social apresentada indica que esta mensagem é incisiva para os poucos "sábios" e "fortes" da Igreja de Corinto, não havendo dúvidas de que eles entenderiam a força destas afirmaçōes. A atitude "meramente humana" que caracterizava sua conduta indica também uma atitude irônica da parte de Paulo. Algumas pessoas procuravam envergonhar e desonrar os membros da comunidade que consideravam socialmente inferiores, mas Paulo inverte esta situação ao afirmar que os "sábios" e "fortes" segundo os padrōes da sabedoria do mundo são envergonhados pelo próprio Deus. A ironia é ainda maior quando o leitor percebe que a cruz, considerada símbolo de vergonha e desonra, torna-se o meio para envergonhar as próprias pessoas que a desprezavam ${ }^{46}$.

Paulo confronta também as pessoas "sábias" e "fortes" que agiam e julgavam as demais pessoas "de maneira meramente humana" com as implicaçôes sociais da cruz. As atitudes de algumas pessoas que se consideravam superiores segundo os valores da "sabedoria deste mundo" eram a causa da discórdia na comunidade ${ }^{47}$. A apresentação da teologia da cruz diz respeito à arrogância destas pessoas, sendo o seu efeito expresso na declaração: "a fim de que nenhuma criatura possa vangloriar-se diante de Deus" $(1,29)$.

Deus revela sua sabedoria e poder na cruz de Cristo e escolhe a fraqueza e loucura do mundo, destruindo todos os fundamentos do orgulho humano ${ }^{48}$. Apesar de criticar a conduta e comportamento impróprio dos coríntios, Paulo não desvaloriza os seus privilégios. Ele reconhece que diferentes grupos pertenciam à comunidade cristã e os encorajava a permanecer na situaçáo em que se encontravam e manter o status social que tinham quando foram chamados por Deus $(1,26 ; 7,17-24)$, mas afirma que em termos da vocação divina, não há diferença entre os coríntios que possuíam um status social elevado e as pessoas mais humildes, entre sábios e loucos, entre ricos e pobres, entre escravos e livres. Paulo lembra aos coríntios que eles eram iguais em Cristo: eram irmãos e irmãs em Cristo, independentemente do lugar social a que pertenciam.

\footnotetext{
${ }^{46}$ Pickett, The Cross in Corinth. The Social Significance of the Death of Jesus, 72-73.

${ }^{47}$ Marshall, Enmity in Corinth. Social Conventions in Paul's Relations with the Corinthians, 187.

${ }^{48}$ Pickett, The Cross in Corinth. The Social Significance of the Death of Jesus, 73-74.
} 


\section{Referências}

Barclay, John M. G. "Thessalonica and Corinth: Social Contrasts in Pauline Christianity". Journal for the Study of the New Testament 47 (1992): 49-74.

Berger, Klaus. Formas Literárias do Novo Testamento. São Paulo: Loyola, 1998.

Best, Ernst. "The Power and Wisdom of God". In Paolo a una Chiesa Divisa (1 Co 14), editado por L. de Lorenzi, 9-39. Roma: Edizioni Abbazia di S. Paolo, 1980.

Clarke, Andrew D. Secular and Christian Leadership in Corinth: A Socio-Historical and Exegetical Study of 1 Corinthians 1-6. Leiden: E. J. Brill, 1993.

Conzelmann, Hans. 1 Corinthians. Philadelphia (PA): Fortress Press, 1975.

De Silva, David A. The Hope of Glory: Honor Discourse and the New Testament Interpretation. Collegeville (MN): The Liturgical Press, 1999.

Donahoe, Kate C. "From Self-praise to Self-boasting: Paul's Unmasking of the Conflicting Rhetoric-Linguistc Phenomena in 1 Corinthians". Tese de Doutorado, University of St. Andrews, St. Andrews (U. K.), 2008.

Fee, Gordon D. The First Epistle to the Corinthians. Grand Rapids (MI): W. B. E. Publishing Co., 1984.

Finney, Mark T. Honour and Conflict in the Ancient World. 1 Corinthians in its GrecoRoman Social Setting. London: Bloomsbury, 2013.

Friesen, Steven J. "Prospects for a Demography of the Pauline Mission: Corinth among the Churches". In Urban Religion in Roman Corinth. Interdisciplinary Approaches, editado por Daniel N. Shovalter e Steven J. Friesen, 351-370. Cambridge (MA): Harvard University Press, 2005.

Hays, Richard B. First Corinthians. Louisville (KY): John Knox Press, 1997.

Heil, John Paul. The Rhetorical Role of Scripture in 1 Corinthians. Atlanta (GA): Society of Biblical Literature Press, 2005.

Horrell, David G. The Social Ethos of the Corinthians Correspondence. Interests and Ideology from 1 Corinthians to 1 Clement. Edinburgh: T \& T Clark, 1996.

Kammler, Hans-Christian. Kreuz und Weisheit. Eine exegetische Untersuchung zu 1 Kor 1,10-3,4. Tübingen: J. C. B. Mohr, 2003.

Kwon, Oh-Young. 1 Corinthians. Reconstructing its Social and Rhetorical Situation. Eugene (OR): Wipf \& Stock, 2010. 
Litfin, Duane. St. Paul's Theology of Proclamation. 1 Corinthians 1-4 and Greco-Roman Rhetoric. Cambridge (U. K.): Cambridge University Press, 1994.

Marshall, Peter. Enmity in Corinth. Social Conventions in Paul's Relations with the Corinthians. Tübingen: J. C. B. Mohr, 1987.

Martin, Dale B. The Corinthian Body. New Haven (CT)-London: Yale University Press, 1995.

Meeks, Wayne A. Os primeiros cristãos urbanos. O mundo social do apóstolo Paulo. São Paulo: Paulus/Academia Cristã, 2011.

Mihaila, Corin. The Paul-Apollos Relationship and Paul's Stance Toward Greco-Roman Rhetoric. Edinburgh: T \& T Clark, 2009.

O’Day, Gail R. “Jeremiah 9:22-23 and 1 Corinthians 1:26-31: A Study in Intertextuality”. Journal of Biblical Literature 109/2 (1990): 259-267.

Okambawa, Wilfrid. Paulus und Sophia. Eine exegestisch-rhetorische Untersuchung zu 1Kor 1,10-31. Frankfurt am Main-Berlin: Peter Lang, 2002.

Pickett, Raymond. The Cross in Corinth. The Social Significance of the Death of Jesus. Sheffield: Sheffield Academic Press, 1997.

Pogoloff, Stephen M. Logos and Sophia. The Rhetorical Situation of 1 Corinthians. Atlanta (GA): Scholars Press, 1992.

Strüder, C. W. Paulus um die Gesinnung Christ. Identität und Entscheidungsfindung aus der Mitte von 1 Kor 1-4. Leuven: Peeters, 2005.

Theissen, Gerd. The Social Setting of Pauline Christianity. Essays on Corinth. Philadelphia (PA): Fortress Press, 1982.

Thiselton, Anthony C. The First Epistle to the Corinthians. Grand Rapids (MI): W. B. E. Publishing Co., 2000.

Voss, Florian. Das Wort vom Kreuz und die menschliche Vernunft. Göttingen: Vandenhoeck \& Ruprecht, 2002.

Witherington III, Ben. Conflict and Community: A Socio-Rhetorical Commentary on 1 and 2 Corinthians. Grand Rapids (MI): Eerdmans, 1995. 